\title{
然 \\ DIÁLOGO COMPETITIVO EM LICITAÇÕES: UMA ANÁLISE SOB A PERSPECTIVA DOS MÚLTIPLOS FLUXOS DE KINGDON
}

\author{
COMPETITIVE DIALOGUE IN GOVERNMENT PROCUREMENT: AN ANALYSIS \\ FROM THE PERSPECTIVE OF KINGDON'S MULTIPLE STREAMS
}

\author{
DIÁLOGO COMPETITIVO EN LICITACIONES: UN ANÁLISIS DESDE LA \\ PERSPECTIVA DE LOS MÚLTIPLES FLUJOS DE KINGDON
}

\author{
Henrico Hernandes Nunes dos Santos ${ }^{1}$ \\ Osvaldo de Freitas Fogatti ${ }^{2}$ \\ Eduardo Meireles ${ }^{3}$
}

\begin{abstract}
Resumo: Avalia como o diálogo competitivo em licitações pode contribuir para aprimorar a produção tecnológica nacional. Desenvolveu-se estudo com aplicação do modelo dos múltiplos fluxos de Kingdon (problemas, soluções e política). Por meio de metodologia exploratória e qualitativa, analisaram-se materiais disponíveis no repositório Science Direct, após critérios objetivos amparados na métrica CitiScore desenvolvida pela Scopus. Os resultados indicaram a possibilidade de estímulo à inovação, com colaboração dos interessados, sustentabilidade, eficiência, mitigação da percepção de riscos e compensação de deficiências administrativas. Detectaram-se questionamentos com relação à eficiência e à eficácia da modalidade licitatória. $\mathrm{O}$ estudo foi parcialmente suficiente para identificação dos limites do diálogo competitivo como mecanismo de estímulo à inovação.
\end{abstract}

Palavra-chave: Diálogo competitivo; Inovação tecnológica; Licitação pública.

\begin{abstract}
The objective is to evaluate how the competitive in government procurement dialogue can contribute to improving national technological production. A study was developed with the application of the Kingdon multiple streams model (problems, solutions and policy). Through exploratory and qualitative methodology, materials available in the Science Direct repository were analyzed, after objective criteria based on the CitiScore metric developed by Scopus. The results indicated the possibility of stimulating innovation, with the collaboration of stakeholders, sustainability, efficiency, mitigating the perception of risks and compensating for administrative deficiencies. Questions were detected regarding the efficiency and effectiveness of the bidding modality. The study was partially sufficient to identify the limits of competitive dialogue as a mechanism to stimulate innovation.
\end{abstract}

Keywords: Competitive dialogue; Government procurement; Technological innovation.

Resumen: El objetivo es evaluar cómo el diálogo competitivo en licitaciones puede contribuir a mejorar la producción tecnológica nacional. Se desarrolló un estudio con la aplicación del modelo de flujos múltiples de Kingdon (problemas, soluciones y política). Mediante metodología exploratoria y cualitativa, se

\footnotetext{
${ }^{1}$ Mestrando em Propriedade Intelectual e Transferência de Tecnologia para a Inovação (PROFNIT), Universidade do Estado de Minas Gerais (UEMG). ORCID: https://orcid.org/0000-0002-9327-3184. Email: henrico.br@gmail.com.

${ }^{2}$ Mestrando em Propriedade Intelectual e Transferência de Tecnologia para a Inovação (PROFNIT), Universidade do Estado de Minas Gerais (UEMG). ORCID: https://orcid.org/0000-0002-5147-2935. Email: fogatti@gmail.com.

3 Doutor em Engenharia Urbana pela Universidade Federal de São Carlos (UFSCAR), coordenador e professor do Mestrado em Propriedade Intelectual e Transferência de Tecnologia para a Inovação (PROFNIT), Universidade do Estado de Minas Gerais (UEMG). ORCID: https://orcid.org/0000-0002-6711-6572. Email: eduardo.meireles@uemg.br.
} 
analizaron los materiales disponibles en el repositorio de Science Direct, siguiendo criterios objetivos respaldados por la métrica CitiScore desarrollada por Scopus. Los resultados indicaron la posibilidad de estimular la innovación, con la colaboración de los grupos de interés, la sostenibilidad, la eficiencia, mitigar la percepción de riesgos y compensar las deficiencias administrativas. Se detectaron dudas sobre la eficiencia y efectividad de la modalidad de licitación. El estudio fue parcialmente suficiente para identificar los límites del diálogo competitivo como mecanismo para estimular la innovación.

Palabras clave: Diálogo competitivo; Innovación tecnológica; Licitación.

\section{Introduçāo}

O desenvolvimento tecnológico brasileiro é questão prioritária em um cenário no qual a economia, o emprego, as comunicações, a gestão urbana e mesmo as relações sociais são cada vez mais dependentes da inovação tecnológica. No entanto, variados entraves fazem com que o Brasil apresente tendência de inovação pouco expressiva, ainda que que seja a nona economia do mundo (WORLD BANK, 2019).

Nesse aspecto, má-governança, instabilidade macroeconômica, exígua cooperação entre o mercado e os polos produtores de pesquisa científica, insuficientes indicadores de educação, inaplicabilidade das políticas públicas existentes para fomento à inovação e à tecnologia, excesso de burocracia e dificuldades para defesa da propriedade intelectual são os embargos mais comumente citados (UNESCO, 2015; EMERGE BRASIL, 2020; TADEU; SANTOS, 2016; IBGE, 2017; CABRAL; SOUSA; CANÊDO-PINHEIRO, 2020; CARVALHO et al., 2017; FORTEC, 2016).

A agenda de capacitação tecnológica torna-se ainda mais premente no atual cenário de desindustrialização e reprimarização da matriz produtiva brasileira, pautado pela retração do papel da indústria na economia e sua substituição pelo mercado de commodities (OREIRO; FEIJÓ, 2010; CANO, 2012; MARCONI, 2015; MAIA, 2020). Somam-se a isso os sinais de desadensamento (ou esgarçamento) produtivo em setores fulcrais para o desenvolvimento tecnológico, como o de informática e eletrônicos, o farmacêutico, o químico e o de produção de veículos que não automóveis, como motocicletas, aeronaves, embarcações navais e equipamentos ferroviários (SARTI; HIRATUKA, 2017; MORCEIRO; GUILHOTO, 2020).

Além dos fatores internos, existem evidências globais no sentido de retorno das cadeias de produção dos países em desenvolvimento para os países de origem, fenômeno conhecido como reshoring, que pode agravar a tendência de desindustrialização nacional (JOHNSON, 2002).

Esse cenário convive com o atual momento de mudança estrutural no eixo tecnológico e produtivo, que se convencionou chamar de Quarta Revolução Industrial ou Indústria 4.0, e cuja força motriz é composta por transformações tecnológicas dos meios de produção da revolução digital e da inteligência artificial (WANG et al., 2020).

Nesse sentido, dificuldades adicionais são postas para a adaptação do setor produtivo brasileiro, porquanto a pesquisa e desenvolvimento de produtos e serviços ligados às tecnologias mais promissoras - internet das coisas e robótica - dependem de infraestrutura adequada, 
insuficiente no Brasil (POPKOVA; RAGULINA, BOGOVIZ, 2019; SCHWAB, 2019).

Determinados ramos da Indústria 4.0 representam janelas de oportunidades para que o Brasil realize processo de catching up, isto é, alcance patamar de riqueza equivalente ao das nações consideradas desenvolvidas (ZAGATO, 2019).

Para caminharem em sentido convergente acerca dos termos econômicos e tecnológicos com as nações desenvolvidas, na linha de estudos sobre o modelo Schumpeteriano de catching up, Lee (2019) argumenta que os países em desenvolvimento devem buscar desvios (ou atalhos - detours) em relação aos caminhos tradicionais, ao citar estratégias para criação de capacitação tecnológica ligadas à inovação.

No caso brasileiro, o ordenamento jurídico impõe condicionantes para a celebração de contratos entre o Poder Público e a iniciativa privada. Ainda que propiciem a seleção de ofertas mais economicamente vantajosas para a Administração Pública, as normas licitatórias nem sempre oferecerão ao gestor a oportunidade de contratar produtos e serviços que estimulem a pesquisa, o desenvolvimento ou a transferência de tecnologia para o país, o que, de certo modo, engessa a adoção das estratégias de catching up e leapfrogging propostas por Lee (2019).

O uso estratégico da aquisição de produtos e serviços como medida de incentivo ao desenvolvimento tecnológico encontra considerável eco na comunidade europeia, sob o nome de Public Procurement for Innovation (PPI), um conjunto de soluções vocacionado a estimular o mercado a produzir inovação por meio do poder de compra estatal (EUROPEAN COMMISSION, 2021).

Dentre os instrumentos de PPI já incorporados no âmbito normativo da União Europeia está o diálogo competitivo, modalidade licitatória na qual todos os aspectos técnicos mais relevantes dos produtos e serviços a serem contratados são previamente discutidos com as empresas potencialmente interessadas. Por um lado, o instrumento torna a fase pré-licitatória mais produtiva, transparente e participativa e, por outro, permite que o Estado utilize as informações técnicas advindas dos diálogos prévios como insumo para a formação de editais que busquem a contratação de soluções inovadoras (FEDERAL MINISTRY FOR ECONOMIC AFFAIRS AND ENERGY, 2017).

A Lei n. 14.133, de $1^{\circ}$ de abril de 2021, também referida como Nova Lei de Licitações e Contratos Administrativos, introduziu o diálogo competitivo ao ordenamento jurídico brasileiro, com aplicação, dentre outras hipóteses, às contratações que versem sobre inovação tecnológica ou técnica (BRASIL, 2021a).

Tendo em conta a inclusão do diálogo competitivo no rol de modalidades licitatórias no Brasil, as seguintes indagações direcionam a presente análise: o diálogo competitivo poderia contribuir para o fomento à produção tecnológica nacional? Quais seriam os resultados esperados e quais seriam seus limites?

Para responder às questões, estruturou-se o trabalho de maneira que a próxima seção 
tratará dos aspectos metodológicos da pesquisa. Em seguida, os referenciais teóricos serão apresentados por meio da demonstração dos aspectos principais de estudos anteriores que tratam da temática abordada. Ao final, se discutirá a implementação do diálogo competitivo como política pública de estímulo à inovação tecnológica, sob a ótica do modelo de múltiplos fluxos de Kingdon (2014), e a correlação de cada fluxo (problemas, soluções e político) com o instrumento licitatório em estudo. Em seguida, serão apresentadas as conclusões e sugestões para futuros estudos.

\section{Procedimentos metodológicos}

Com base em metodologia de pesquisa essencialmente exploratória e qualitativa, elaborou-se referencial teórico para subsidiar a análise e discussão do tema sob o método dos múltiplos fluxos de Kingdon (2014). Para tanto, realizaram-se pesquisas no repositório Science Direct, entre os dias 9 e 16 de fevereiro de 2021, com os termos em língua inglesa "competitive dialogue" (diálogo competitivo) e "innovation" (inovação), e recorte temporal circunscrito aos últimos vinte anos. Em seguida, os artigos foram classificados segundo o fator de impacto do periódico, com base na métrica CitiScore, desenvolvida pelo banco de dados Scopus, e as 35 primeiras publicações foram analisadas. A partir da análise e filtragem dos artigos que não tinham relação com a temática de desenvolvimento tecnológico, elaborou-se tabela com os estudos pertinentes e seus principais apontamentos em relação ao instrumento do diálogo competitivo.

Em seguida, o diálogo competitivo foi analisado sob a ótica do modelo de múltiplos fluxos de Kingdon (2014), teoria desenvolvida em 1984 por John Kingdon, que compreende a formação de agendas de políticas públicas com base na interação de três fluxos de atores e processos: problemas, soluções (ou alternativas) e fluxo político (SABATIER, 2007; MORAN; REIN; GOODIN, 2008; DUNN; 2018; GOTTEMS et al., 2013).

O fluxo de problemas se ocupa de situações que geram mais debates entre as autoridades. Seus vetores são indicadores, eventos-foco e feedbacks (SABATIER, 2007; GOTTEMS et al., 2013). Por sua vez, o fluxo de soluções representa as propostas em discussão para solução de problemas, e sua apreciação no cenário político depende das viabilidades técnicas, da aceitação pela sociedade (ou comunidade) e da tolerância dos custos (KINGDON, 2014; GOTTEMS et al., 2013). E o fluxo político trata dos atores mais relevantes na análise das políticas públicas, e se desdobra na análise do clima nacional, das forças políticas organizadas e das mudanças no governo (KINGDON, 2014; GOTTEMS et al., 2013).

Para subsunção da realidade brasileira aos variados critérios de análise do ferramental teórico proposto, recorreu-se à análise de artigos advindos de diversos bancos de dados (Scielo, Science Direct, Web of Science e Google Scholar), da legislação federal brasileira, de normas internacionais, incluídas normas comunitárias da União Europeia, de manuais e de documentos técnicos de órgãos públicos brasileiros e estrangeiros, todos referenciados ao final. 


\section{Referencial teórico e revisão bibliográfica}

Diante dos critérios estabelecidos no tópico anterior, os resultados obtidos foram 57 artigos. Após identificação dos 35 principais artigos, a partir da métrica CitiScore, seguida da análise qualitativa de cada publicação, 13 documentos foram excluídos, por não se enquadrarem no escopo do trabalho (RAMOS et al., 2021; WILLEMS et al., 2020; COLLINS, 2020; VELTER et al., 2020; TAMMI; SAASTAMOINEN; REIJONEN, 2019; SLOOT; HEUTINK; VOORDIJK, 2019; CHEN; ARDILA-GOMEZ; FRAME, 2017; PACHECO-BLANCO; BASTANTE-CECA, 2016; ERNST et al., 2016; KOPPENJAN, 2015; NEČASKÝ et al., 2014; EDITORS-JACCSD, 2013; WINCH, 2013).

Os 22 artigos remanescentes, reputados relevantes segundo os critérios propostos, são apresentados na Tabela 1:

Tabela 1 - Descrição dos artigos mais relevantes e respectivas contribuições

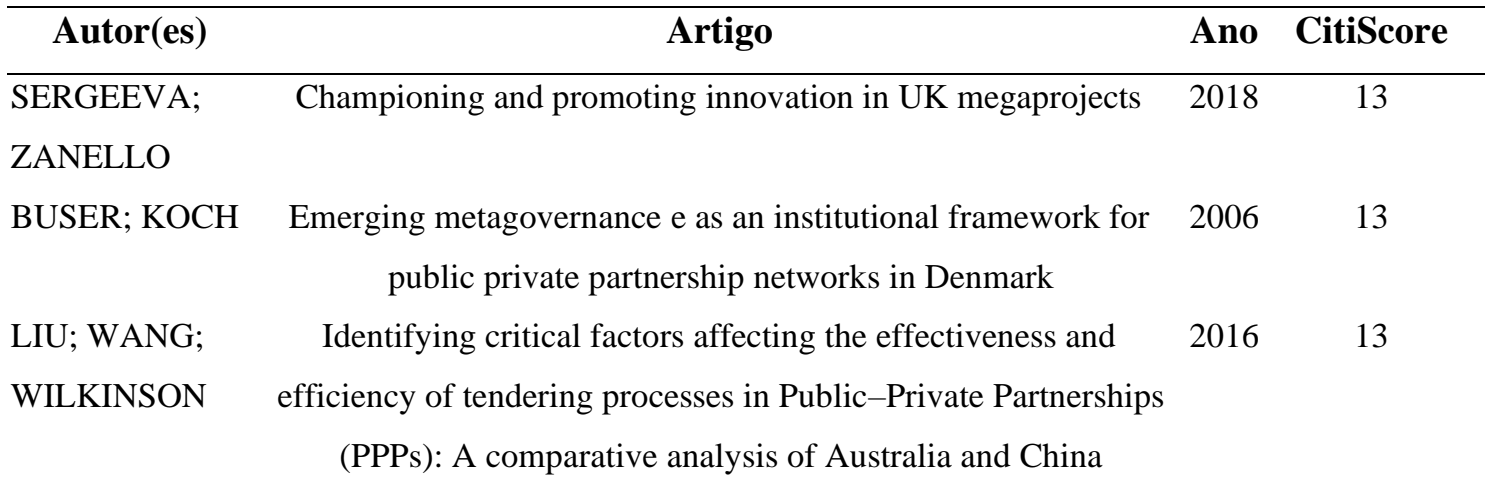

LENFERINK; Towards sustainable infrastructure development through integrated $2013 \quad 13$

TILLEMA; contracts: Experiences with inclusiveness in Dutch infrastructure

ARTS projects

WALKER; Coping with uncertainty and ambiguity through team collaboration 2017

DAVIS; $\quad$ in infrastructure projects

STEVENSON

CUI et al.

Review of studies on the public-private partnerships (PPP) for

2018

infrastructure projects

CLERCK;

An ex ante bidding model to assess the incentive creation

2016

DEMEULEMEE capability of a public-private partnership pipeline

STER

UYARRA et al.

Barriers to innovation through public procurement: A supplier

$$
\text { perspective }
$$

UTTAM; ROOS

$$
\text { Competitive dialogue procedure for sustainable public }
$$

$$
\text { procurement }
$$

HUFEN; DE Getting the incentives right. Energy performance contracts as a 2016

BRUIJN tool for property management by local government 
SÖNNICHSEN; Review of green and sustainable public procurement: Towards 2020

CLEMENT circular public procurement

POT

The governance challenge of implementing long-term 2021 sustainability objectives with present-day investment decisions

BRUNO et al. The promise of Best Value Procurement: governance and 2018 (in)stability of specifications within an innovative biogas project

GOEL; $\quad$ Sustainability integration in the management of construction 2019

GANESH; $\quad$ projects: A morphological analysis of over two decades' research

KAUR literature

UYARRA et al. Public procurement, innovation and industrial policy: Rationales, 2020 roles, capabilities and implementation

EDLER; $\quad$ Public procurement and innovation-Resurrecting the demand side2007

GEORGHIOU

BARLOW; The private finance initiative, project form and design innovation. 2008

KÖBERLE-

The UK's hospitals programme.

GAISER

SOE;

Agile local governments: Experimentation before implementation 2018

DRECHSLER

KRUCOFF et al. Medical Device Innovation: Prospective Solutions for an 2012

Ecosystem in Crisis: Adding a Professional Society Perspective

GEORGHIOU et Policy instruments for public procurement of innovation: Choice, 2014

al.

design and assessment

O'BRIEN; $\quad$ Localism and energy: Negotiating approaches to embedding 2010

HOPE resilience in energy systems

BROCK et al. Light the way for smart cities: Lessons from Philips Lighting 2019

Fonte: Elaborada pelos autores.

No aspecto metodológico, 12 artigos foram embasados precipuamente em estudos de caso, ao passo que os demais se valeram da análise documental e de revisão bibliográfica. Pôdese perceber que os debates sobre o diálogo envolviam cinco temáticas ou eixos específicos, apesar de correlacionados, quais sejam: (i) PPPs e concessões (BUSER; KOCH, 2006; LIU; WANG; WILKINSON, 2016; LENFERINK; TILLEMA; ARTS, 2013; CUI et al., 2018; CLERCK; DEMEULEMEESTER, 2016); (ii) gerenciamento de riscos contratuais (GOEL; GANESH; KAUR, 2019); (iii) sustentabilidade (UTTAM; ROSS, 2014; HUFEN; DE BRUIJN, 2016; BRUNO et al., 2018; GOEL; GANESH; KAUR, 2019; POT, 2021; O’BRIEN; HOPE, 2010); (iv) cooperação ou colaboração entre as partes contratantes (SOE; DRECHSLER, 2018; SERGEEVA; ZANELLO, 2018; KRUCOFF et al., 2012; SÖNNICHSEN; CLEMENT, 2020) e (v) fomento à inovação (BARLOW; KÖBERLE-GAISER, 2008; EDLER; GEORGHIOU, 2007; 
UYARRA et al., 2020; UYARRA et al., 2014; BROCK et al., 2019; GEORGHIOU et al., 2014).

Um dos artigos sinalizou que o diálogo competitivo foi relevante para a celebração de parcerias público-privadas (PPP) na Dinamarca (BUSER; KOCH, 2006), o que vai ao encontro das conclusões do trabalho de Liu, Wang e Wilkinson (2016), que, ao analisar diversos modelos de licitação utilizados em âmbito global, elencou o diálogo competitivo como uma das espécies de licitações competitivas realizadas em múltiplos estágios, destacando ainda que licitações em múltiplos estágios são mais vantajosas em termos de inovação.

Validando o trabalho de Buser e Koch (2006), Lenferink, Tillema e Arts (2013) apontaram que o diálogo competitivo constitui espécie de licitação que canaliza as demandas dos contratos denominados Design-Build-Finance-Maintain (DBFM), utilizados nos Países Baixos, similares aos contratos de concessão do direito brasileiro. Em síntese, esses três estudos sinalizam para a tendência de utilização do diálogo competitivo em licitações envolvendo concessões e PPPs, contratos cujo objeto é mais complexo ou envolve valores vultosos.

Ainda na temática das PPPs, Cui et al. (2018) identificaram que o diálogo competitivo foi um fator relevante para maior morosidade nessa espécie de contrato, ao passo que Clerck e Demeulemeester (2016) ressaltaram a escassez de trabalhos acadêmicos sobre licitações na modalidade diálogo competitivo envolvendo PPPs.

Quatro estudos salientaram o papel do diálogo competitivo para estimular a cooperação entre a Administração Pública e os licitantes (SOE; DRECHSLER, 2018; SERGEEVA; ZANELLO, 2018; KRUCOFF et al., 2012; SÖNNICHSEN; CLEMENT, 2020). Destaca-se que estudo de Krucoff et al. (2012) assinalou que os diálogos prévios entre as partes podem contribuir para redução de determinadas barreiras, como a falta de recursos, e que associações profissionais estão bem posicionadas para intermediar e auxiliar as partes interessadas na realização de diálogos competitivos. Soe e Drechsler (2018), ao estudarem o projeto de construção de projeto integrado de tráfego urbano entre Helsinki, na Finlândia, e Tallin, na Estônia, citaram a utilização do diálogo competitivo como ferramenta de execução da fase piloto do certame, na qual motoristas, especialistas em tráfego e autoridades foram ouvidos pela Administração Pública.

Dos trabalhos analisados, seis deles dão enfoque à sustentabilidade (UTTAM; ROSS, 2014; HUFEN; DE BRUIJN, 2016; BRUNO et al., 2018; GOEL; GANESH; KAUR, 2019; POT, 2021; O'BRIEN; HOPE, 2010). Nessa seara, Uttam e Ross (2014), a partir de estudo de caso relativo ao uso de procedimento de diálogo competitivo para a construção da ponte Kvarnholmen link, em Estocolmo, Suécia, concluíram que o diálogo competitivo pode funcionar como mecanismo de inclusão da sustentabilidade nas contratações públicas, e recomendaram que a Administração Pública utilize objetos provisórios de contratação (provisionally preferred solution - PPS) para estimular os licitantes a aderirem aos padrões de sustentabilidade desejados.

A correlação entre diálogo competitivo e licitações verdes foi também abordada por Hufen e De Bruijn (2016), que, em estudo de caso sobre contratos de produtos e serviços de 
conservação de energia na cidade holandesa de Roterdã, concluíram que o diálogo competitivo, associado à formação de parceria público-privada e à celebração de contrato de gestão (management and performance contract - MPC), apresentou melhorias em relação ao contrato anterior celebrado por Roterdã relativo à infraestrutura de conservação de energia. Por fim, outros dois trabalhos analisados se referem ao diálogo competitivo como exemplo de instrumento para licitações sustentáveis (BRUNO et al., 2018; GOEL; GANESH; KAUR, 2019).

Não obstante, um dos artigos analisados refuta as conclusões dos citados trabalhos, com base nas premissas de que o conceito de sustentabilidade é ambíguo, o que dificulta sua implementação por meio de aquisições públicas. Conclui também que restrições orçamentárias impostas a nível político também estimulam o gestor a buscar produtos ou serviços não sustentáveis (POT, 2021).

A partir de estudo de caso relativo ao uso de contrato Private Finance Initiative - PFI, similar ao contrato brasileiro de concessão, com o objetivo de construir ou reformar moradias para idosos no nordeste da Inglaterra, O’Brien e Hope (2010) observaram que o diálogo competitivo começou a atrair a atenção de alguns dos desenvolvedores de inovação no mercado energético e, no caso estudado, permitiu que os gestores explicassem aos licitantes as razões pelas quais os projetos exigiam a utilização de energia limpa e oferecessem a eles informações específicas sobre a realidade local e sobre os recursos disponíveis.

Sob o prisma do fomento à inovação, Barlow e Köberle-Gaiser (2008), embasados em estudo de caso relativo à construção de seis hospitais no Reino Unido, em parcerias firmadas pela Administração Pública com empresas privadas, concluíram que o uso do poder de compra do Estado para estímulo à inovação - que pode ser feito por intermédio do diálogo competitivo - não provê benefícios automáticos, tanto em inovação quanto em eficiência. É importante salientar que esse estudo não descarta o papel do diálogo competitivo no fomento à inovação, mas sugere que a importância das PPIs, em geral, deve ser contextualizada com outros aspectos contratuais que limitam a inovação, especialmente as cláusulas de redução de riscos.

Edler e Georghiou (2007), em estudo sobre as Diretivas 2004/17 e 18/2004 da Comunidade Europeia, elencaram o diálogo competitivo como instrumento que possibilita debates prévios entre a Administração Pública e os fornecedores sobre aspectos técnicos e competitivos do objeto do certame, constituindo instrumento de fomento à inovação. A seu turno, Uyarra et al. (2020) estudaram os diversos papéis desempenhados pelas aquisições de produtos e serviços pela Administração Pública, dentre eles o estímulo à inovação, e citaram o diálogo competitivo como exemplo de forma de relacionamento precoce com o mercado, para incentivo ao desenvolvimento de soluções inovadoras.

O trabalho de Brock et al. (2019), embasado em estudo de caso da implementação de soluções tecnológicas para cidades inteligentes em quatro municípios holandeses, reportou que a cidade de Eindhoven, ciente da dificuldade em definir todos os requisitos necessários para uma 
cidade inteligente nas propostas iniciais da licitação, utilizou procedimento de diálogo competitivo que se mostrou exitoso, e permitiu a contratação de consórcio que foi capaz de implementar sistema de iluminação que permanece aberto para que outros fornecedores façam melhorias incrementais. Em sentido contrário, estudo de Georghiou et al. (2014), respaldado na análise dos instrumentos utilizados pela OCDE para incentivo à inovação, e também da análise de pesquisa com 800 fornecedores do setor público do Reino Unido, concluiu que políticas de incentivo à inovação, dentre elas a utilização de licitações na modalidade diálogo competitivo, não foram suficientes para remover as barreiras existentes.

Sob a premissa de que o diálogo competitivo constitui instrumento adequado ao fomento da inovação, trabalho de Uyarra et al. (2014) explorou dados colhidos em pesquisa com fornecedores da Administração Pública no Reino Unido para expressar a correlação entre a falta de capacitação e o uso dessa modalidade licitatória.

Acerca da temática da percepção de riscos, três dos artigos analisados respaldam a conclusão de que o diálogo competitivo pode contribuir para a percepção e gerenciamento de entraves nos contratos públicos, por conta da comunicação estabelecida entre as partes (GOEL; GANESH; KAUR, 2019; SÖNNICHSEN; CLEMENT, 2020). Porém, um dos estudos observados refutou essa conclusão, dando ênfase em outros instrumentos para essa finalidade, como a conformidade com o orçamento e a necessidade de imposição de metas (POT, 2021).

Dentre outras tópicos debatidos nos estudos analisados, Sergeeva e Zanello (2018), a partir de avaliação de megaprojetos no Reino Unido, no caso, o Bank Station Capacity Upgrade, citaram que o diálogo competitivo permitiu a exploração, desde do início, de novas ideias para a melhor estratégia de entrega da obra e maximização de seus benefícios, além de prover o tempo necessário para obtenção da colaboração de fornecedores na supply chain. Por sua vez, Sönnichsen e Clement (2020) destacaram que procedimentos pré-comerciais, parcerias públicoprivadas e diálogo competitivo são instrumentos que facilitam a seleção não discriminatória de fornecedores em licitações de projetos complexos e de grande vulto, avaliando ainda que o diálogo competitivo deve ser utilizado em contratos particularmente complexos nos aspectos técnicos, físicos, financeiros e jurídicos, nos quais pode ampliar a assertividade do gestor ao permitir a criação de relacionamentos produtivos com os possíveis fornecedores, além de mitigar a percepção do risco e indicar as soluções mais inovadoras. Um dos trabalhos analisados identificou o diálogo competitivo como exemplo de adaptação do modelo de gestão de projetos Integrated Project Delivery (IPD), caracterizado pelo alto nível de colaboração entre as partes envolvidas (WALKER; DAVIS; STEVENSON, 2017). 


\section{Análise e discussão dos resultados}

\subsection{Fluxo dos problemas}

O fluxo ou corrente dos problemas baseia-se na premissa de que nem todas as questões socialmente relevantes chamam a atenção das pessoas responsáveis pela gestão da agenda governamental, a depender, segundo Kingdon (2014), de indicadores governamentais, de crises e do feedback das ações de governo.

Diversos indicadores apontam para a necessidade de adoção de políticas públicas de incentivo à inovação no Brasil. A última Pesquisa de Inovação (PINTEC) do Instituto Brasileiro de Geografia e Estatística (IBGE), referente ao período 2015-2017, revela redução de 36\% para 33,6\% na taxa de inovação relativa à pesquisa anterior, de 2012-2014 (IBGE, 2017; DE NEGRI et al., 2020). De Negri et al. (2020) apontam que relevantes indicadores da PINTEC denotam queda no cenário de inovação, como investimentos em pesquisa e desenvolvimento (P\&D) em relação ao produto interno bruto (PIB), e investimentos em $\mathrm{P} \& \mathrm{D}$ em relação à receita líquida de vendas (RLV). Com base nos dados divulgados em 2017 pelo Ministério da Ciência, Tecnologia, Inovações e Comunicações (MCTIC), Koeller (2020) salientou a significativa redução de investimentos governamentais em $\mathrm{P} \& \mathrm{D}$, com diminuição dos aportes disponibilizados para $\mathrm{o}$ orçamento da Coordenação de Aperfeiçoamento de Pessoal de Nível Superior (CAPES) e do Conselho Nacional de Desenvolvimento Científico e Tecnológico (CNPq).

A recessão econômica ocorrida no Brasil, advinda das crises política e fiscal experimentadas no país a partir de 2014, constitui relevante evento para estímulo à uma agenda de inovação tecnológica, pois há evidente correlação entre desenvolvimento tecnológico e crescimento dos índices de produtividade (VELOSO, 2017).

Hodiernamente, a crise sanitária mundial decorrente da pandemia de Covid-19 impõe o estímulo governamental à pesquisa de vacinas, remédios, testes diagnósticos e equipamentos médicos, como respiradores e equipamentos de proteção (DE NEGRI; KOELLER, 2020).

Esses eventos foram capazes de influenciar o debate político no sentido da adoção de reformas no âmbito das aquisições públicas e, de certo modo, podem justificar a rápida tramitação do Projeto de Lei (PL) n. 4.253/2020 da Câmara dos Deputados (BRASIL, 2020), que deu origem à vigente Lei n. 14.133/2021, salientando-se que a novel legislação passou a elencar o incentivo à inovação tecnológica e ao desenvolvimento socioeconômico como objetivos do procedimento licitatório (BRASIL, 2021a).

Acerca do feedback das ações governamentais, variados estudos discorrem sobre a necessidade de modernização da antiga Lei de Licitações e Contratos - Lei n. 8.666/1993 (BRASIL, 1993), para melhoria das normas de integridade (DIAS, 2020; SANTOS; SOUZA, 2016), flexibilização em determinadas situações (JUSTEN FILHO, 2020), redução de formalismos ou ritos ineficientes (FIUZA; MEDEIROS, 2013) e exploração de funções atípicas das licitações, como seu papel regulatório (OLIVEIRA, 2012; FERRAZ, 2009). 


\subsection{Fluxo das soluções}

Ao tratar do fluxo de soluções, Kingdon (2014) menciona o conjunto de ideias ou propostas aventadas por agentes estatais, acadêmicos, grupos de interesse, para solução de problemas. Esse aspecto é regido por movimentos caóticos de surgimento, modificação e recombinação, à vista das contingências e peculiaridades do debate público, de modo que algumas ideias são descartadas e outras são alçadas ao patamar da política. A viabilidade técnica, a aceitação pela comunidade e os custos toleráveis são fatores que, no entanto, auxiliam a explicar o debacle ou sucesso de determinadas soluções.

No campo da viabilidade técnica, pode-se afirmar que o diálogo competitivo encontra respaldo jurídico, econômico e social, tratando-se de instrumento apto para utilização no país. Na seara jurídica, constata-se que há compatibilidade material entre a Constituição Federal e os dispositivos da Lei n. 14.133/2021 que incluíram o diálogo competitivo no ordenamento, na medida em que a própria Constituição determina a adoção de procedimentos licitatórios para realização de contratações públicas e possui extenso corpo de normas programáticas de incentivo à ciência, tecnologia e inovação. Sob as perspectivas jurídica, econômica e social, tanto o PLS n. 559/2013 do Senado Federal (SF), como o projeto no qual foi apensado ao chegar à Câmara dos Deputados - PL n. 1.292/1995, receberam pareceres favoráveis como resultado dos trabalhos conjuntos das Comissões de Constituição, Justiça e Cidadania (CCJ/SF), de Assuntos Econômicos (CAE/SF) e de Serviços e Infraestrutura (CI/SF) do Senado Federal (BRASIL, 2013b), e da Comissão Especial da Câmara dos Deputados (BRASIL, 2018).

A literatura jurídica brasileira apresenta comentários favoráveis ao instituto, como a legitimação de práticas que já ocorriam informalmente (NIEBUHR et al., 2020; LOUREIRO, 2019), os ganhos em versatilidade e margem de atuação para os gestores (NOHARA, 2018; OLIVEIRA, 2017; ROCHA, 2017; VAZ, 2020), a possibilidade de solução de demandas administrativas específicas ou complexas (SILVA, 2020; ROCHA, 2017; ZAGO; RODRIGUES, 2019; LOUREIRO, 2019; ROSILHO, 2021), a efetiva implementação de mecanismo de discussão e disputa entre os próprios licitantes (JUSTEN FILHO, 2015). Crítica pertinente foi ventilada por Rosilho (2021), para o qual a opinião de órgãos de controle, prevista no artigo 32, $\S 1^{\circ}$, XII, do PL n. 4.253/2020, acabaria adquirindo caráter vinculante e engessaria as contratações, implicando sequestro da atividade administrativa pela fiscalizatória. Tal crítica foi parcialmente encampada pela Presidência da República, que vetou o dispositivo sob o argumento de que a propositura feria a distribuição de competências prevista no artigo 71 da Constituição Federal, além de violar o princípio da separação de poderes (BRASIL, 2021b).

Acerca do critério de aceitação pela comunidade, pode-se argumentar que a própria atividade legiferante é um indicativo de que a sociedade, por meio de seus representantes democraticamente eleitos, anuiu ao instituto debatido. Além disso, a espécie licitatória em comento é aplicada na Comunidade Europeia, onde encontra previsão legal desde 2004, ano em 
que o Parlamento Europeu adotou a Diretiva n. 2004/2018.

Ademais, o diálogo competitivo tem custos toleráveis, na medida em que se trata de política pública essencialmente instrumental, que não impõe despesas de vulto, a exceção de gastos associados à burocracia para realização e registro dos debates prévios, pré-seleção dos licitantes e eventual contratação de profissionais para assessoramento técnico da comissão de contratação (art. 32, § 1º, VI e XI, da Lei n. 14.133/2021) (BRASIL, 2021a). Estudos citados na sistematização da literatura indicam que o diálogo competitivo pode ampliar a assertividade do gestor (SÖNNICHSEN; CLEMENT, 2020; GOEL; GANESH; KAUR, 2019), promover a eficiência (KRUCOFF et al., 2012) e propiciar adjudicações sustentáveis (UTTAM; ROOS, 2014; HUFEN; DE BRUIJN, 2016; BRUNO et al., 2018), de onde se conclui, por desdobramento lógico, provável redução dos gastos públicos inerentes aos contratos celebrados por meio do diálogo competitivo.

\subsection{Fluxo político}

O fluxo político trata das dinâmicas próprias do poder, ou seja, do variado plexo de forças políticas organizadas ou eventos que influenciam congressistas e governantes (KINGDON, 2014; CAPELLA, 2005). Sua sistematização no modelo de múltiplos fluxos ocorre mediante estudo (i) do humor nacional (national mood), algo como o senso ou sentimento da sociedade civil, vale dizer, da opinião pública, (ii) da atuação das forças políticas organizadas, que compreendem a atuação de grupos de pressão, a mobilização e o comportamento político das elites, (iii) e das mudanças no governo, componente complexo, que engloba desde alterações no quadro de gestores/legisladores até a forma de atuação de órgãos, agências ou comitês estatais (KINGDON, 2014; GOTTEMS et al., 2013).

Demandas da sociedade, de elites políticas e de grupos de pressão por reformulações na revogada Lei n. 8.666/1993 remontam ao início de sua vigência. Entre 1993 a 1995, a Lei foi objeto de 28 propostas legislativas de alteração e, no período total de vigência (vinte oito anos), 648 propostas. Para fins de comparação, o Código dos Contratos Públicos de Portugal teve 16 modificações promovidas por espécies normativas diversas desde sua entrada em vigor (29/1/2008), enquanto a Lei n. 8.666/1993, no mesmo período, foi objeto de 47 alterações (PORTUGAL, 2008; BRASIL, 1993).

Isso exigiu mudanças na Lei de Licitações que convergissem com os estímulos estatais à inovação tecnológica, o que propiciou a edição de expressivo conjunto de normas, notadamente as Leis n. 9.648/1998, 10.973/2004, 11.107/2005, 11.196/2005, 12.715/2012, 12.873/2013, 13.204/2015 e 13.243/2016 (BRASIL, 1998; BRASIL, 2004; BRASIL, 2005a; BRASIL, 2005b; BRASIL, 2012; BRASIL, 2013a; BRASIL, 2015; BRASIL, 2016), e a Medida Provisória n. 495/2010, convertida na Lei n. 12.349/2010 (BRASIL, 2010a; BRASIL, 2010b).

A dinâmica política também pode ser explicada pela percepção dos congressistas de que 
a Lei de Licitações anterior constituía entrave à inovação. Essa conclusão, corroborada por juristas (JUSTEN FILHO, 2010; OLIVEIRA, 2012; FERRAZ, 2009; RAINHO, 2018), ecoou nos debates realizados ao longo dos trabalhos parlamentares que culminaram na aprovação e subsequente promulgação da Lei n. 14.133/2021, conforme abaixo:

Também estamos agora com uma nova modalidade, que é o diálogo competitivo. Esse diálogo competitivo vem se somar às outras modalidades já existentes. Vai facilitar a contratação de empresas que tenham propostas que venham a resolver problemas identificados pelos entes federativos. É muito boa, é um avanço muito grande. Isso já é praticado em outros países do Primeiro Mundo. (ROCHA, 2019, p. 59)

Por último, o que para mim é o mais importante, vamos, de uma vez por todas, tornar o Estado brasileiro capaz de comprar inovação. Através de dispositivos de diálogo competitivo e de procedimentos de manifestação de interesse, nós vamos conseguir contratar startups, contratar soluções para problemas cuja solução não conhecemos ainda. Isso vai tornar muito mais fácil conseguir que a inteligência coletiva da sociedade brasileira ajude o Governo a resolver os seus próprios problemas. Nós estamos, como eu disse, há 24 anos tentando modificar essa lei. Então, eu peço a todos aqui que, sim, discutamos essa matéria, mas que a votemos em breve, porque ela é muito importante. O Brasil inteiro está esperando por uma nova Lei de Licitações e um novo sistema de compras públicas. (RIGONI, 2019a, p. 242).

E, para mim, o mais importante de tudo: o Estado brasileiro até então era incapaz de comprar inovação, por conta da Lei $\mathrm{n}^{\circ}$ 8.666. Com essa nova Lei de Licitações, através do diálogo competitivo e da proposta de manifestação de interesse, que são dois dispositivos muito importantes que trazemos e que são inovações, teremos a possibilidade de contratar inovação. E vai ser muito mais fácil para o Prefeito, para o Governador e, obviamente, para todos os gestores públicos contratarem inovação e serem mais eficientes. (RIGONI, 2019b, p. 257).

O empenho polítio e social para a modernização da legislação licitatória, associado aos reclames no sentido de que o diálogo competitivo poderia conferir a flexibilidade necessária para a promoção de políticas de incentivo à inovação, explica a rápida tramitação, nos anos de 2019 e 2020, do PL 4.253/2020, que foi sancionado em abril deste ano, com 17 vetos, pelo Presidente da República.

\section{Conclusão}

O presente estudo buscou analisar o instituto do diálogo competitivo em licitações como medida de fomento à inovação tecnológica no Brasil, ao perquirir os resultados esperados e os limites à aplicação desse instrumento para tal finalidade. A partir de revisão sistemática da literatura, concluiu-se que o diálogo competitivo poderá estimular a inovação, a colaboração entre as partes envolvidas no certame, a sustentabilidade, a seleção não discriminatória dos concorrentes e a eficiência, além de ampliar a assertividade e mitigar a percepção de risco pelos gestores, bem como compensar deficiências administrativas.

No âmbito do recorte metodológico adotado, alguns estudos questionaram a eficácia ou 
eficiência do diálogo competitivo como instrumento capaz de fomentar a inovação e a sustentabilidade, ou de reduzir a percepção de riscos pelos gestores. Essa percepção merece destaque para demonstrar que não há unanimidade ou consenso sobre o tema, de maneira que o aprimoramento das discussões dá margem a debates e estudos futuros em relação às conclusões destes trabalhos.

Dessa forma, identificou-se que vetores nos três fluxos teóricos propostos contribuíram para a adoção legislativa do diálogo competitivo, no Brasil, como medida de estímulo à inovação. No fluxo dos problemas, baixos indicadores de inovação no Brasil, associados à recessão econômica enfrentada pelo país desde 2014, à crise sanitária derivada da pandemia Covid-19, e ao feedback de especialistas na área de contratações públicas acerca da necessidade de modernização da revogada Lei de Licitações se uniram para a formação da agenda em torno da adoção de instrumentos administrativos mais adequados ao mercado de inovação.

Sobre o fluxo das soluções, averiguou-se, com base na análise legislativa, em documentos públicos relativos à tramitação e debates legislativos do PL 4.253/2020, que o diálogo competitivo encontra amparos jurídico, econômico e social para implementação no país, é socialmente tolerado e apresenta perspectiva de redução de custos para a Administração Pública.

Acerca do fluxo político, a dinâmica de considerável rejeição da sociedade, de elites políticas e de grupos de pressão à sistemática da Lei n. 8.666/1993, bem como a busca, por esses mesmos grupos, de soluções legislativas de incentivo à inovação, contribuiu para explicar a célere aprovação, nos últimos dois anos, do PL 4.253/2020.

A revisão sistemática de literatura e a análise do tema pela teoria dos múltiplos fluxos de Kingdon foram parcialmente suficientes para identificação dos limites do diálogo competitivo como ferramenta de estímulo à inovação. Dessa forma, aponta-se a possibilidade de elaboração de estudos de caso com enfoque na análise das eventuais limitações do instrumento em tela.

\section{Referências}

BARLOW, James; KÖBERLE-GAISER, Martina. The private finance initiative, project form and design innovation: The UK's hospitals programme. Research Policy, v. 37, n. 8, p. 13921402, 2008. Disponível em: https://doi.org/10.1016/j.respol.2008.04.027. Acesso em: 18 fev. 2021.

BRASIL. Câmara dos Deputados. Comissão Especial. Parecer da Comissão Especial destinada a proferir parecer ao Projeto de Lei n. 1292, de 1995. Brasília, DF: Câmara dos Deputados, 2018. Disponível em:

https://www.camara.leg.br/proposicoesWeb/fichadetramitacao?idProposicao=2188308. Acesso em: 24 maio 2021.

BRASIL. Lei n. 8.666, de 21 de junho de 1993. Regulamenta o art. 37, inciso XXI, da Constituição Federal, institui normas para licitações e contratos da Administração Pública e dá outras providências. Brasília, DF: Câmara dos Deputados, 2018. Disponível em: https://www2.camara.leg.br/legin/fed/lei/1993/lei-8666-21-junho-1993-322221-norma-pl.html. Acesso em: 17 fev. 2021. 
BRASIL. Lei n. 9.648, de 27 de maio de 1998. Altera dispositivos das Leis n. 3.890-A, de 25 de abril de 1961, n. 8.666, de 21 de junho de 1993, n. 8.987, de 13 de fevereiro de 1995, n. 9.074, de 7 de julho de 1995, n. 9.427, de 26 de dezembro de 1996, e autoriza o Poder Executivo a promover a reestruturação da Centrais Elétricas Brasileiras - ELETROBRÁS e de suas subsidiárias e dá outras providências. Brasília, DF: Presidência da República, 1998. Disponível em: http://www.planalto.gov.br/ccivil_03/leis/19648cons.htm. Acesso em: 17 fev. 2021.

BRASIL. Lei n. 10.973, de 2 de dezembro de 2004. Dispõe sobre incentivos à inovação e à pesquisa científica e tecnológica no ambiente produtivo e dá outras providências. Brasília, DF: Presidência da República, 2004. Disponível em:

http://www.planalto.gov.br/ccivil_03/_ato2004-2006/2004/lei/110.973.htm. Acesso em: 17 fev. 2021.

BRASIL. Lei n. 11.107, de 6 de abril de 2005. Dispõe sobre normas gerais de contratação de consórcios públicos e dá outras providências. Brasília, DF: Presidência da República, 2005. Disponível em: http://www.planalto.gov.br/ccivil_03/_ato2004-2006/2005/lei/111107.htm. Acesso em: 17 fev. 2021.

BRASIL. Lei n. 11.196, de 21 de novembro de 2005. Institui o Regime Especial de Tributação para a Plataforma de Exportação de Serviços de Tecnologia da Informação - REPES, o Regime Especial de Aquisição de Bens de Capital para Empresas Exportadoras - RECAP e o Programa de Inclusão Digital; dispõe sobre incentivos fiscais para a inovação tecnológica, dentre outras disposições. Brasília, DF: Presidência da República, 2005. Disponível em: http://www.planalto.gov.br/ccivil_03/_ato2004-2006/2005/lei/111196.htm. Acesso em: 17 fev. 2021.

BRASIL. Lei n. 12.349, de 15 de dezembro de 2010. Altera as Leis n. 8.666, de 21 de junho de 1993, n. 8.958, de 20 de dezembro de 1994, e n. 10.973, de 2 de dezembro de 2004; e revoga o $\S 1^{\circ}$ do art. $2^{\circ}$ da Lei n. 11.273, de 6 de fevereiro de 2006. Brasília, DF: Presidência da República, 2010. Disponível em: http://www.planalto.gov.br/ccivil_03/_Ato20072010/2010/Lei/L12349.htm. Acesso em: 17 fev. 2021.

BRASIL. Lei n. 12.715, de 17 de setembro de 2012. Altera a alíquota das contribuições previdenciárias sobre a folha de salários devidas pelas empresas que especifica; institui o Programa de Incentivo à Inovação Tecnológica e Adensamento da Cadeia Produtiva de Veículos Automotores, o Regime Especial de Tributação do Programa Nacional de Banda Larga para Implantação de Redes de Telecomunicações, o Regime Especial de Incentivo a Computadores para Uso Educacional, o Programa Nacional de Apoio à Atenção Oncológica e o Programa Nacional de Apoio à Atenção da Saúde da Pessoa com Deficiência; restabelece o Programa Um Computador por Aluno; altera o Programa de Apoio ao Desenvolvimento Tecnológico da Indústria de Semicondutores, instituído pela Lei n. 11.484, de 31 de maio de 2007; dentre outras disposições. Brasília, DF: Presidência da República, 2012. Disponível em: http://www.planalto.gov.br/ccivil_03/_ato2011-2014/2012/lei/112715.htm. Acesso em: 17 fev. 2021.

BRASIL. Lei n. 12.873, de 24 de outubro de 2013. Autoriza a Companhia Nacional de Abastecimento a utilizar o Regime Diferenciado de Contratações Públicas - RDC, instituído pela Lei n. 12.462, de 4 de agosto de 2011, para a contratação de todas as ações relacionadas à reforma, modernização, ampliação ou construção de unidades armazenadoras próprias destinadas às atividades de guarda e conservação de produtos agropecuários em ambiente natural; dentre outras disposições. Brasília, DF: Presidência da República, 2013. Disponível em: http://www.planalto.gov.br/ccivil_03/_ato2011-2014/2013/lei/112873.htm. Acesso em: 17 fev. 2021.

BRASIL. Lei n. 13.204, de 14 de dezembro de 2015. Altera a Lei n. 13.019, de 31 de julho de 2014, "que estabelece o regime jurídico das parcerias voluntárias, envolvendo ou não transferências de recursos financeiros, entre a administração pública e as organizações da sociedade civil, em regime de mútua cooperação, para a consecução de finalidades de interesse 
público; define diretrizes para a política de fomento e de colaboração com organizações da sociedade civil; institui o termo de colaboração e o termo de fomento; dentre outras disposições. Brasília, DF: Presidência da República, 2015. Disponível em: http://www.planalto.gov.br/ccivil_03/_ato2015-2018/2015/lei/113204.htm. Acesso em: 17 fev. 2021.

BRASIL. Lei n. 13.243, de 11 de janeiro de 2016. Dispõe sobre estímulos ao desenvolvimento científico, à pesquisa, à capacitação científica e tecnológica e à inovação; dentre outras disposições. Brasília, DF: Presidência da República, 2016. Disponível em: http://www.planalto.gov.br/ccivil_03/_ato2015-2018/2016/lei/113243.htm. Acesso em: 17 fev. 2021.

BRASIL. Lei n. 14.133, de $1^{\circ}$ de abril de 2021. Lei de Licitações e Contratos Administrativos. Brasília, DF: Senado Federal, 2021. Disponível em: http://www.planalto.gov.br/ccivil_03/_ato2019-2022/2021/lei/L14133.htm. Acesso em: 23 abr. 2021.

BRASIL. Medida Provisória n. 495, de 19 de julho de 2010. Altera as Leis n. 8.666, de 21 de junho de 1993, n. 8.958, de 20 de dezembro de 1994, e n. 10.973, de 2 de dezembro de 2004, e revoga o $\S 1^{\circ}$ do art. $2^{\circ}$ da Lei n. 11.273, de 6 de fevereiro de 2010. Brasília, DF: Presidência da República, 2005. Disponível em: http://www.planalto.gov.br/ccivil_03/_ato2007-

2010/2010/mpv/495.htm. Acesso em: 17 fev. 2021.

BRASIL. Mensagem n. 118, de $\mathbf{1}^{\circ}$ de abril de 2021. Comunica ao Presidente do Senado Federal os vetos presidenciais ao Projeto de Lei n. 4.253/2020 da Câmara dos Deputados. Brasília, DF: Presidência da República, 2021. Disponível em: http://www.planalto.gov.br/ccivil_03/_ato2019-2022/2021/Msg/VEP/VEP-118.htm. Acesso em: 23 abr. 2021.

BRASIL. Projeto de Lei do Senado n. 559, de 2013. Institui normas para licitações e contratos da Administração Pública e dá outras providências. Brasília, DF: Senado Federal, 2013. Disponível em: https://www25.senado.leg.br/web/atividade/materias/-/materia/115926. Acesso em: 17 fev. 2021.

BRASIL. Projeto de Lei n. 4.253, de 2020. Estabelece normas gerais de licitação e contratação para as administrações públicas diretas, autárquicas e fundacionais da União, dos Estados, do Distrito Federal e dos Municípios; altera as Leis n. 13.105, de 16 de março de 2015 (Código de Processo Civil), n. 8.987, de 13 de fevereiro de 1995, e n. 11.079, de 30 de dezembro de 2004, e o Decreto Lei n. 2.848, de 7 de dezembro de 1940 (Código Penal); e revoga dispositivos da Lei n. 12.462, de 4 de agosto de 2011, e as Leis n. 8.666, de 21 de junho de 1993, e n. 10.520, de 17 de julho de 2002. Brasília, DF: Senado Federal, 2020. Disponível em:

https://legis.senado.leg.br/sdleggetter/documento?dm=8879045\&ts=1611621651945\&disposition=inline. Acesso em: $17 \mathrm{fev}$. 2021.

BROCK, Kati et al. Light the way for smart cities: Lessons from Philips Lighting. Technological Forecasting and Social Change, v. 142, p. 194-209, 2019. Disponível em: https://doi.org/10.1016/j.techfore.2018.07.021. Acesso em: 18 fev. 2021.

BRUNO, Teo et al. The promise of Best Value Procurement: Governance and (in) stability of specifications within an innovative biogas project. Journal of Cleaner Production, v. 172, p. 1465-1475, 2018. Disponível em: https://doi.org/10.1016/j.jclepro.2017.10.251. Acesso em: 18 fev. 2021.

BUSER, Martine; $\mathrm{KOCH}$, Christian. Emerging metagovernance as an institutional framework for public private partnership networks in Denmark. International Journal of Project Management, v. 24, n. 7, p. 548-556, 2006. Disponível em: https://doi.org/10.1016/j.ijproman.2006.07.001. Acesso em: 18 fev. 2021.

CABRAL, Bernardo Pereira; SOUSA, Filipe Lage; CANÊDO-PINHEIRO, Mauricio. Assessing 
the impacts of innovation barriers: a qualitative analysis of Brazil's natural resources industry. Resources Policy, v. 68, p. 101-136, 2020. Disponível em:

https://doi.org/10.1016/j.resourpol.2020.101736. Acesso em: 08 fev. 2021.

CANO, Wilson. A desindustrialização no Brasil. Economia e sociedade, v. 21, n. esp., p. 831851, 2012. Disponível em: https://doi.org/10.1590/S0104-06182012000400006. Acesso em: 9 fev. 2021.

CAPELLA, Ana Cláudia Niedhardt. Formação da agenda governamental: perspectivas teóricas. In: ENCONTRO ANUAL DA ANPOCS, 23., Caxambu. Anais [...]. Caxambu: ANPOCS, 2005, p. 1-35. Disponível em: https://www.anpocs.com/index.php/papers-29-encontro/gt25/gt19-21/3789-acapella-formacao/file. Acesso em: 19 fev. 2021.

CARVALHO, Rodrigo Baroni et al. Panorama da inovação no Brasil: análise baseada na perspectiva da competitividade global. Revista Gestão \& Tecnologia, v. 17, n. 4, p. 129-151, 2017. Disponível em: https://doi.org/10.20397/2177-6652/2017.v17i4.1276. Acesso em: 19 fev. 2021.

CHEN, Yang; ARDILA-GOMEZ, Arturo; FRAME, Gladys. Achieving energy savings by intelligent transportation systems investments in the context of smart cities. Transportation Research Part D: Transport and Environment, v. 54, p. 381-396, 2017. Disponível em: https://doi.org/10.1016/j.trd.2017.06.008. Acesso em: 23 abr. 2021.

CLERCK, Dennis; DEMEULEMEESTER, Erik. An ex ante bidding model to assess the incentive creation capability of a public-private partnership pipeline. International Journal of Project Management, v. 34, n. 1, p. 117-131, 2016. Disponível em: https://doi.org/10.1016/j.ijproman.2015.10.007. Acesso em: 18 fev. 2021.

COLLINS, Beck. "It's not talked about": The risk of failure in practice in sustainability experiments. Environmental Innovation and Societal Transitions, v. 35, p. 77-87, 2020. Disponível em: https://doi.org/10.1016/j.eist.2020.02.008. Acesso em: 18 fev. 2021.

CUI, Caiyun et al. Review of studies on the public-private partnerships (PPP) for infrastructure projects. International Journal of Project Management, v. 36, n. 5, p. 773-794, 2018. Disponível em: https://doi.org/10.1016/j.ijproman.2018.03.004. Acesso em: 18 fev. 2021.

DE NEGRI, Fernanda et al. Redução drástica na inovação e no investimento em P\&D no brasil: o que dizem os indicadores da pesquisa de inovação 2017. Brasília, DF: Ministério da Economia, Diretoria de Estudos e Políticas Setoriais de Inovação e Infraestrutura, 2020.

DE NEGRI, Fernanda; KOELLER, Priscila. Políticas públicas para pesquisa e inovação em face da crise da Covid-19. Brasília, DF: Ministério da Economia, Diretoria de Estudos e Políticas Setoriais de Inovação e Infraestrutura, 2020.

DIAS, Lidiane Dutra. Projeto da Nova Lei de Licitações: uma análise dos principais avanços e críticas. Revista Vertentes do Direito, v. 7, n. 2, p. 50-80, 2020. Disponível em: https://doi.org/10.20873/uft.2359-0106.2020.v7n2.p50-80. Acesso em: 17 fev. 2021.

DUNN, William N. Public policy analysis: An Integrated Approach. Routledge, New York: [S.n.],: 2018.

EDLER, Jakob; GEORGHIOU, Luke. Public procurement and innovation - Resurrecting the demand side. Research policy, v. 36, n. 7, p. 949-963, 2007. Disponível em: https://doi.org/10.1016/j.respol.2007.03.003. Acesso em: 18 fev. 2021.

EDITORS - JACCSD. A Review of JACC Articles on the Topic of Heart Rhythm Disorders: 2011-2012. Journal of the American College of Cardiology, v. 62, n. 21, 451-519, 2013. Disponível em: https://doi.org/10.1016/j.jacc.2013.09.026. Acesso em: 18 fev. 2021.

EMERGE BRASIL. Horizonte Inovação \& Ciência: O perfil da inovação de base científica. 2021.Disponível em: https://emergebrasil.in/horizonte/. Acesso em: 17 fev. 2021. 
ERNST, L. et al. Sustainable urban transformation and sustainability transitions; conceptual framework and case study. Journal of Cleaner Production, v. 112, p. 2988-2999, 2016. Disponível em: https://doi.org/10.1016/j.jclepro.2015.10.136. Acesso em: 18 fev. 2021.

EUROPEAN COMMISSION. Public Procurement of Innovative Solutions. 2021. Disponível em: https://ec.europa.eu/digital-single-market/en/public-procurement-innovative-solutions. Acesso em: 19 fev. 2021.

FEDERAL MINISTRY FOR ECONOMIC AFFAIRS AND ENERGY. Public procurement of innovation. $2^{\text {nd }}$ ed. Berlin: Federal Ministry for Economic Affairs and Energy (BMWi), 2017. Disponível em:

https://procure2innovate.eu/fileadmin/user_upload/Documents/KOINNO_PublicProcurementof Innovation.pdf. Acesso em: 19 fev. 2021.

FERRAZ, Luciano. Função regulatória da licitação. A\&C Revista de Direito Administrativo \& Constitucional, v. 9, n. 37, p. 133-142, 2009. Disponível em: http://dx.doi.org/10.21056/aec.v9i37. Acesso em: 17 fev. 2021.

FIUZA; Eduardo Pedral Sampaio; MEDEIROS, Bernardo Abreu. A reforma da Lei 8.666/93 e do arcabouço legal de compras públicas no Brasil: contribuições do Ipea à Consulta Pública do Senado. Brasília, DF: Ministério da Economia, Diretoria de Estudos e Políticas Setoriais de Inovação e Infraestrutura, 2013.

FÓRUM NACIONAL DE GESTORES DE INOVAÇÃO E TRANSFERÊNCIA DE TECNOLOGIA - FORTEC. Relatório anual da Pesquisa FORTEC de Inovação - Ano Base 2016. Pesquisa FORTEC de inovação. Disponível em: http://fortec.org.br/documentos/relatorios/. Acesso em: 19 fev. 2021.

GEORGHIOU, Luke et al. Policy instruments for public procurement of innovation: Choice, design and assessment. Technological Forecasting and Social Change, v. 86, p. 1-12, 2014. Disponível em: https://doi.org/10.1016/j.techfore.2013.09.018. Acesso em: 18 fev. 2021.

GOEL, Ashish; GANESH, L. S.; KAUR, Arshinder. Sustainability integration in the management of construction projects: A morphological analysis of over two decades' research literature. Journal of Cleaner Production, v. 236, p. 117676, 2019. Disponível em: https://doi.org/10.1016/j.jclepro.2019.117676. Acesso em: 18 fev. 2021.

GOTTEMS, Leila Bernarda Donato et al. O modelo dos múltiplos fluxos de Kingdon na análise de políticas de saúde: aplicabilidades, contribuições e limites. Saúde e Sociedade, São Paulo, v. 22, n. 2, p. 511-520. Disponível em: http://dx.doi.org/10.1590/S0104-12902013000200020. Acesso em: 15 fev. 2021.

HUFEN, Hans; DE BRUIJN, Hans. Getting the incentives right. Energy performance contracts as a tool for property management by local government. Journal of Cleaner Production, v. 112, p. 2717-2729, 2016. Disponível em: https://doi.org/10.1016/j.jclepro.2015.10.036. Acesso em: 18 fev. 2021.

\section{INSTITUTO BRASILEIRO DE GEOGRAFIA E ESTATÍSTICA. PINTEC - Pesquisa de Inovação 2017. Disponível em:}

https://biblioteca.ibge.gov.br/visualizacao/livros/liv101706_notas_tecnicas.pdf. Acesso em: 18 fev. 2021.

JOHNSON, Christopher H. De-industrialization and Globalization. International Review of Social History, v. 47, n. S10, p. 3-33, 2002. Disponível em:

https://doi.org/10.1017/S0020859002000767. Acesso em: 9 fev. 2021.

JUSTEN FILHO, Marçal. Comentários à lei de licitações e contratos administrativos. 14 ed. São Paulo: Dialética, 2010.

JUSTEN FILHO, Marçal. Mas temos muito ainda a falar sobre licitação. Gazeta do Povo, Direito e Justiça, , 2015. Disponível em: https://www.gazetadopovo.com.br/vidapublica/justica-e-direito/colunistas/marcal-justen-filho/mas-temos-muito-ainda-a-falar-sobre- 
licitacao-0k320vk5ryh9zn8tdrguqlrzm/. Acesso em: 17 fev. 2021.

JUSTEN FILHO, Marçal. Um novo modelo de licitações e contratações administrativas? A MP 926 pode funcionar como experimento para a reforma das licitações. In: JUSTEN FILHO et al. Covid 19 e o direito brasileiro. São Paulo: Justen, Pereira, Oliveira \& Talamini, 2020. p. 2133.

LOUREIRO, Caio de Souza. Nova lei de licitações: o que esperar quando se está esperando? Consultor Jurídico, Opinião. Disponível em: https://www.conjur.com.br/2019-out-28/caiosouza-loureiro-esperar-lei-licitacoes. Acesso em: 17 fev. 2021.

KINGDON, John W. Agendas, Alternatives and Public Policies. 2 ed. Essex: Pearson Education Limited, 2014.

KOELLER, Priscila. Investimentos Federais em Pesquisa e Desenvolvimento: Estimativas para o Período 2000-2020. Brasília, DF: Ministério da Economia, Diretoria de Estudos e Políticas Setoriais de Inovação e Infraestrutura, 2020.

KOPPENJAN, Joop FM. Public-private partnerships for green infrastructures. Tensions and challenges. Current Opinion in Environmental Sustainability, v. 12, p. 30-34, 2015. Disponível em: https://doi.org/10.1016/j.cosust.2014.08.010. Acesso em: 18 fev. 2021.

KRUCOFF, Mitchell W. et al. Medical device innovation: prospective solutions for an ecosystem in crisis: adding a professional society perspective. JACC: Cardiovascular Interventions, v. 5, n. 7, p. 790-796, 2012. Disponível em: https://doi.org/10.1016/j.jcin.2012.03.023. Acesso em: 18 fev. 2021.

LEE, Keun. The art of economic catch-up: Barriers, detours and leapfrogging in innovation systems. Cambridge: Cambridge University Press, 2019.

LENFERINK, Sander; TILLEMA, Taede; ARTS, Jos. Towards sustainable infrastructure development through integrated contracts: Experiences with inclusiveness in Dutch infrastructure projects. International journal of project management, v. 31, n. 4, p. 615-627, 2013. Disponível em: https://doi.org/10.1016/j.ijproman.2012.09.014. Acesso em: 18 fev. 2021.

LIU, Tingting; WANG, Yan; WILKINSON, Suzanne. Identifying critical factors affecting the effectiveness and efficiency of tendering processes in Public-Private Partnerships (PPPs): A comparative analysis of Australia and China. International Journal of project management, v. 34, n. 4, p. 701-716, 2016. Disponível em: https://doi.org/10.1016/j.ijproman.2016.01.004. Acesso em: 18 fev. 2021.

MAIA, Bento Antunes de Andrade. Há desindustrialização no Brasil? Um estudo da abordagem clássica e de análises alternativas entre 1998 e 2014. Economia e Sociedade, v. 29, n. 2, p. 549579, 2020. Disponível em: https://doi.org/10.1590/1982-3533.2020v29n2art08. Acesso em: 9 fev. 2021.

MARCONI, Nelson; Estrutura Produtiva e Desenvolvimento Econômico. In: MARCONI, Nelson et al. (org.). Indústria e Desenvolvimento Produtivo no Brasil. Rio de Janeiro: Elsevier, 2015.p. 32-49.

MORCEIRO, Paulo César; GUILHOTO, Joaquim José Martins. Adensamento produtivo e esgarçamento do tecido industrial brasileiro. Economia e Sociedade, Campinas, v. 29, n. 3, p. 835-860. Disponível em: https://doi.org/10.1590/1982-3533.2020v29n3art07. Acesso em: 9 fev. 2021.

MORAN, Michael; REIN, Martin; GOODIN, Robert E. The Oxford handbook of public policy. Oxford: Oxford University Press, 2008.

NEČASKÝ, Martin et al. Linked data support for filing public contracts. Computers in Industry, v. 65, n. 5, p. 862-877, 2014. Disponível em: https://doi.org/10.1016/j.compind.2013.12.006. Acesso em: 18 fev. 2021.

NIEBUHR, Joel de Menezes et al. Nova lei de licitações e contratos. Florianópolis: Zênite 
Editora, 2020. Disponível em: https://www.zenite.blog.br/wp-content/uploads/2020/12/NovaLei-de-Licitac\%CC\%A7o\%CC\%83es-e-Contratos-Administrativos.pdf. Acesso em: 17 fev. 2021.

NOHARA, Irene. Diálogo competitivo. Direito Administrativo, 2018. Disponível em: https://direitoadm.com.br/dialogo-competitivo/\#_. Acesso em: 17 fev. 2021.

O'BRIEN, Geoff; HOPE, Alex. Localism and energy: Negotiating approaches to embedding resilience in energy systems. Energy policy, v. 38, n. 12, p. 7550-7558, 2010. Disponível em: https://doi.org/10.1016/j.enpol.2010.03.033. Acesso em: 18 fev. 2021.

OLIVEIRA, Rafael Carvalho Rezende. Licitações e contratos administrativos: teoria e prática. Rio de Janeiro: Método, 2012.

OLIVEIRA, Rafael Sérgio de. O diálogo competitivo do projeto de lei de licitação e contrato brasileiro. Portal Licitação e Contrato. 2017. Disponível em:

http://licitacaoecontrato.com.br/assets/artigos/artigo_download_2.pdf. Acesso em: 17 fev. 2021.

OREIRO, José Luis; FEIJO, Carmem A. Desindustrialização: conceituação, causas, efeitos e o caso brasileiro. Brazilian Journal of Political Economy, São Paulo, v. 30, n. 2, p. 219-232. Disponível em: https://doi.org/10.1590/S0101-31572010000200003. Acesso em: 9 fev. 2021.

ORGANIZAÇÃO DAS NAÇÕES UNIDAS PARA A EDUCAÇÃO, A CIÊNCIA E A CULTURA. Relatório de Ciência da UNESCO: rumo a 2030 - visão geral e cenário brasileiro. Paris: UNESCO, 2015. Disponível em: https://unesdoc.unesco.org/ark:/48223/pf0000235407_por.page=40. Acesso em: 18 fev. 2021.

PACHECO-BLANCO, Bélgica; BASTANTE-CECA, María José. Green public procurement as an initiative for sustainable consumption. An exploratory study of Spanish public universities. Journal of Cleaner Production, v. 133, p. 648-656, 2016. Disponível em: https://doi.org/10.1016/j.jclepro.2016.05.056. Acesso em: 18 fev. 2021.

POPKOVA, Elena G.; RAGULINA, Yulia V.; BOGOVIZ, Aleksei V. Industry 4.0: Industrial revolution of the 21st century. Cham: Springer, 2019.

PORTUGAL. Decreto-Lei n. 18, de 29 de janeiro de 2008. Aprova o Código dos Contratos Públicos. Lisboa: Assembleia da República, 2008. Disponível em: https://dre.pt/legislacaoconsolidada/-/lc/34455475/view. Acesso em: 17 fev. 2021.

POT, Wieke D. The governance challenge of implementing long-term sustainability objectives with present-day investment decisions. Journal of Cleaner Production, v. 280, p. 124-135, 2021. Disponível em: https://doi.org/10.1016/j.jclepro.2020.124475. Acesso em: 18 fev. 2021.

RAINHO, Renata Vaz Marques Costa. Entraves legais e normativos para licitação e contratação em ciência, tecnologia e inovação. In: CONGRESSO DE CIÊNCIA, TECNOLOGIA E INOVAÇÃO: POLÍTICAS E LEIS, 1., Belo Horizonte. Anais [...]. Belo Horizonte: 2018. Disponível em: https://www.even3.com.br/anais/observalei/131565-entraves-legais-enormativos-para-licitacao-e-contratacao-em-ciencia-tecnologia-e-inovacao-/. Acesso em: 24 maio 2021.

RAMOS, Victor et al. Legal framework of marine renewable energy: A review for the Atlantic region of Europe. Renewable and Sustainable Energy Reviews, v. 137, p. 110608, 2021. Disponível em: https://doi.org/10.1016/j.rser.2020.110608. Acesso em: 18 fev. 2021.

RIGONI, Felipe. Discurso. Diário da Câmara dos Deputados, v. 74, 15 de maio de 2019. Disponível em:

https://www.camara.leg.br/internet/sitaqweb/TextoHTML.asp?etapa $=5 \&$ nuSessao=101.2019\&n uQuarto $=118250 \&$ nuOrador $=5 \&$ nuInsercao $=5 \& \mathrm{dtHorario}$ Quarto $=20: 24 \& \mathrm{sgFaseSessa0}=$ OD $\&$ Data $=14 / 05 / 2019 \&$ txApelido=FELIPE\%20RIGONI,\%20PSB-

ES\&txFaseSessao=Ordem $\% 20 \mathrm{do} \% 20$ Dia\&txTipoSessao=Deliberativa\%20Extraordin $\% \mathrm{C} 3 \% \mathrm{~A} 1$ ria\%20-\%20CD\&dtHoraQuarto=20:24\&txEtapa=. Acesso em: 24 maio 2021. 
RIGONI, Felipe. Diário da Câmara dos Deputados, v. 74, 4 de junho de 2019. Disponível em: https://www.camara.leg.br/internet/sitaqweb/TextoHTML.asp?etapa $=5 \&$ nuSessao=136.2019\&n uQuarto $=130580 \&$ nuOrador $=4 \&$ nuInsercao $=4 \& d$ tHorarioQuarto $=20: 48 \& \operatorname{sg}$ FaseSessao $=$ OD \& Data $=04 / 06 / 2019 \&$ txApelido=FELIPE\%20RIGONI,\%20PSB-

ES\&txFaseSessao=Ordem\%20do\%20Dia\&txTipoSessao=Deliberativa\%20Extraordin\%C3\%A1 ria\%20-\%20CD\&dtHoraQuarto=20:48\&txEtapa=. Acesso em: 24 maio 2021.

ROCHA, Hildo. Diário da Câmara dos Deputados, 74, 26 de junho de 2019. Disponível em: https://www.camara.leg.br/internet/SitaqWeb/TextoHTML.asp?etapa $=5 \& n u S e s s a o=170.2019 \&$ nuQuarto $=142488 \&$ nuOrador $=7 \&$ nuInsercao $=7 \&$ dtHorarioQuarto $=15: 08 \& \operatorname{sg} F a s e S e s s a 0=P E \&$ Data=26/06/2019. Acesso em: 24 maio 2021.

ROCHA, Marcelo Dantas. Anotações sobre o PLC 6.814/2017: principais aspectos da proposta da nova Lei Geral de Licitações. Fórum de Contratação e Gestão Pública - FCGP, Belo Horizonte, v. 16, n. 190. Disponível em: https://dspace.almg.gov.br/handle/11037/25389. Acesso em: 19 fev. 2021.

ROSILHO, André. TCU e o diálogo competitivo na nova Lei de Licitações. JOTA, São Paulo, 2021. Disponível em: https://www.jota.info/opiniao-e-analise/colunas/controle-publico/tcu-e-odialogo-competitivo-na-nova-lei-de-licitacoes-17022021. Acesso em: 24 maio 2021.

SABATIER, Paul. Theories of the Policy Process. Cambridge: Westview Press, 2007.

SANTOS, Franklin Brasil; SOUZA, Kleberson Roberto de. Como combater a corrupção em licitações: detecção e prevenção de fraudes. Belo Horizonte: Fórum, 2016.

SARTI, Fernando; HIRATUKA, Célio. Desempenho recente da indústria brasileira no contexto de mudanças estruturais domésticas e globais. . Texto para discussão: Instituto de Economia da UNICAMP, Campinas, n. 290, p. 1-38, 2017. Disponível em:

http://www.eco.unicamp.br/docprod/downarq.php?id=3510\&tp=a. Acesso em: 19 fev. 2021.

SCHWAB, Klaus. A quarta revolução industrial. São Paulo: Edipro, 2019.

SERGEEVA, Natalya; ZANELLO, Chiara. Championing and promoting innovation in UK megaprojects. International Journal of Project Management, v. 36, n. 8, p. 1068-1081, 2018. Disponível em: https://doi.org/10.1016/j.ijproman.2018.09.002. Acesso em: 18 fev. 2021.

SILVA, Pablo Francesco Rodrigues da. Análise luso-brasileira dos contratos administrativosprincipais pontos de convergência e de divergência entre os ordenamentos. Revista da Advocacia Pública Federal, v. 4, n. 1, 2020. Disponível em: https://seer.anafenacional.org.br/index.php/revista/article/view/118. Acesso em: 17 fev. 2021.

SLOOT, R. N. F.; HEUTINK, A.; VOORDIJK, J. T. Assessing usefulness of 4D BIM tools in risk mitigation strategies. Automation in construction, v. 106, p. 102881, 2019. Disponível em: https://doi.org/10.1016/j.autcon.2019.102881. Acesso em: 18 fev. 2021.

SOE, Ralf-Martin; DRECHSLER, Wolfgang. Agile local governments: Experimentation before implementation. Government Information Quarterly, v. 35, n. 2, p. 323-335, 2018.

Disponível em: https://doi.org/10.1016/j.giq.2017.11.010. Acesso em: 18 fev. 2021.

SÖNNICHSEN, Sönnich Dahl; CLEMENT, Jesper. Review of green and sustainable public procurement: Towards circular public procurement. Journal of Cleaner Production, v. 245, p. 118901, 2020. Disponível em: https://doi.org/10.1016/j.jclepro.2019.118901. Acesso em: 18 fev. 2021.

TADEU, Hugo Ferreira Braga; SANTOS, Eduardo Stock dos. O que seria a Indústria 4.0? Boletim da Fundação Dom Cabral, 2016. Disponível em: http://acervo.ci.fdc.org.br/AcervoDigital/Relat\%C3\%B3rios\%20de\%20Pesquisa/Relat\%C3\%B3 rios\%20de $\% 20$ Pesquisa $\% 202016 / 0 \% 20 q u e \% 20$ seria\%20a\%20ind\%C3\%BAstria\%204.0\%20fev\%202016.pdf. Acesso em: $17 \mathrm{fev}, 2021$.

TAMMI, Timo; SAASTAMOINEN, Jani; REIJONEN, Helen. Public procurement as a vehicle 
of innovation-What does the inverted-U relationship between competition and innovativeness tell us? Technological Forecasting and Social Change, v. 153, p. 119922, 2020. Disponível em: https://doi.org/10.1016/j.techfore.2020.119922. Acesso em: 18 fev. 2021.

UTTAM, Kedar; ROOS, Caroline Le Lann. Competitive dialogue procedure for sustainable public procurement. Journal of Cleaner Production, v. 86, p. 403-416, 2015. Disponível em: https://doi.org/10.1016/j.jclepro.2014.08.031. Acesso em: 18 fev. 2021.

UYARRA, Elvira et al. Public procurement, innovation and industrial policy: Rationales, roles, capabilities and implementation. Research Policy, v. 49, n. 1, p. 103844, 2020. Disponível em: https://doi.org/10.1016/j.respol.2019.103844. Acesso em: 18 fev. 2021.

UYARRA, Elvira et al. Barriers to innovation through public procurement: A supplier perspective. Technovation, v. 34, n. 10, p. 631-645, 2014. Disponível em: https://doi.org/10.1016/j.technovation.2014.04.003. Acesso em: 18 fev. 2021.

VAZ, Tania Patricia de Lara. Os incentivos em contratos públicos de obras e serviços: a perspectiva da Law and Economics. Revista Jurídica Luso-Brasileira, v. 6, n. 1, 1319-1387, 2020. Disponível em: https://www.cidp.pt/revistas/rjlb/2020/1/2020_01_1319_1387.pdf. Acesso em: 17 fev. 2021.

VELOSO, Fernado. Lenta recuperação e agenda de reformas. In: VELLOSO, Raul et al. Recessão, crise estadual e da infraestrutura: para onde vai a economia brasileira? Rio de Janeiro: Instituto Nacional de Altos Estudos - INAE, 2017.

VELTER, M. G. E. et al. Sustainable business model innovation: The role of boundary work for multi-stakeholder alignment. Journal of Cleaner Production, v. 247, p. 119497, 2020. Disponível em: https://doi.org/10.1016/j.jclepro.2019.119497. Acesso em: 18 fev. 2021.

WALKER, Derek H. T.; DAVIS, Peter R.; STEVENSON, Andrew. Coping with uncertainty and ambiguity through team collaboration in infrastructure projects. International Journal of Project Management, v. 35, n. 2, p. 180-190, 2017. Disponível em: https://doi.org/10.1016/j.ijproman.2016.11.001. Acesso em: 18 fev. 2021.

WANG, Lu et al. What nurtures fourth industrial revolution? An investigation of economic and social determinants of technological innovation in advanced economies. Technological Forecasting and Social Change, v. 161, p. 120305, 2020. Disponível em: https://doi.org/10.1016/j.techfore.2020.120305. Acesso em: 11 fev. 2021.

WILLEMS, Thijs et al. Practices of isolation: The shaping of project autonomy in innovation projects. International journal of project management, v. 38, n. 4, p. 215-228, 2020. Disponível em: https://doi.org/10.1016/j.ijproman.2020.03.004. Acesso em: 18 fev. 2021.

WINCH, Graham M. Three domains of project organising. International journal of project management, v. 32, n. 5, p. 721-731, 2014. Disponível em:

https://doi.org/10.1016/j.ijproman.2013.10.012. Acesso em: 18 fev. 2021.

WORLD BANK. GDP (current US\$): World Bank national accounts data, and OECD National Accounts data files. 2021. Disponível em:

https://data.worldbank.org/indicator/NY.GDP.MKTP.CD?most_recent_value_desc=true. Acesso em: 19 fev. 2021.

ZAGATO, Ligia. Ainda é possível que os países em desenvolvimento façam seu catching up no século XXI? Brazilian Journal of Political Economy, São Paulo, v. 39, n. 3, p. 527-543. Disponível em: http://dx.doi.org/10.1590/0101-35172019-2849. Acesso em: 19 fev. 2021.

ZAGO, Marina; RODRIGUES, Fernanda. O que o diálogo competitivo agrega às contratações públicas? Consultor Jurídico. Disponível em: https://www.conjur.com.br/2019-nov11/opiniao-dialogo-competitivo-agrega-contratacoes-publicas. Acesso em: 17 fev. 2021.

Artigo submetido em: 2021-04-29; reapresentado em: 2021-05-24, aceito em: 2021-05-28 